\title{
Aggregation-Induced Emission Enhancement of Polysilole Nanoaggregates
}

\author{
Seunghyun Jang, Sung Gi Kim, Daehyuk Jung, Hyungjun Kwon, Jinwoo Song, \\ Sungdong Cho, Young Chun Ko, and Honglae Sohn ${ }^{\circ}$ \\ Department of Chemistry, Chosun Universit, Gwangju 501-759. Korea . E-mail: hsohnochosumackr \\ - Deparment of Nano-Chemical Enwironmental Engineering. Daebul Chiversin, Chonnam $526-702$. Korea \\ Received March 27, 2006
}

Key Words : Polysilole nanoaggregates. Emission enhancement

Polysiloles have recently received much attention ${ }^{1}$ because of their unusual electronic properties. These unusual optical and electrical properties can be useful in electronic devices. such as electron transporting materials. ${ }^{2}$ light-emitting diodes (LEDs) ${ }^{3 \cdot 5}$ and chemical sensors. ${ }^{6.7}$ Poly (2.3.4.5-tetraphenyl)siloles (1) possess both 2.3,4.5-tetraphenyl-1-silacyclopenta2.4-diene and $\mathrm{Si}$-Si backbone that their absorptions exhibit at $314 \mathrm{~cm}$. However the unsaturated five-membered ring of the silole shifts their optical absorption and emission spectra into the visible spectral region at 364 and $520 \mathrm{~mm}$. respectively.

The aggregation of highly emissive organics and polymers into a solid state causes an emission-quenching effect since the aggregation of molecules forms less emissive species such as excimers. ${ }^{8}$ Reduction of emission efficiency in the solid state has been a major problem in device applications of light-emitting organic molecules. Many attempts to prevent aggregate formation have been made through chemical. physical and engineering approaches. In contrast. few results on aggregation-induced emission (AIE) properties have been recently reported. ${ }^{9.12}$

Herein. we report an aggregation-induced emission enhancement of polysiloles. The syintheses of 1 . dichloro(tetraphenyl)silole (2a) and dimethyl(tetraphenyl)silole (2b) were reported previously. The reduction of $2 \mathrm{a}$ with lithium gave molecular weights $\left(M_{*}\right)$ of $5500\left(M_{0} / M_{\mathrm{n}}=1.1\right.$ determined by SEC). Fluorescence emission and excitation spectra were recorded on a Perkin-Elmer Luminescence Spectrometer LS 50B. The solvents were determined to be free of emitting impurities prior to use. The concentration of polysilole aggregates for the fluorescence measurement was $10 \mu \mathrm{g} / \mathrm{L}$. 2a and $2 \mathbf{b}$ emit 380 and $425 \mathrm{~nm}$. respectively. However polysilole 1 shows enission near $520 \mathrm{~nm}$ with excitation at $340 \mathrm{~nm}$. Nanoaggregates of 1 are prepared by rapid precipitation from water solution by the injection of THF solution containing polysilole. This procedure is different from the previous report ${ }^{11}$ and gives better monodisperse for any given water volume fraction. Polysilole aggregate exhibits a nearly identical emission band. however polysilole nanoaggregates are more highly fluorescent than polysiloles at identical concentration. A photograph of polysiloles in THF solution (left) and polysilole nanoaggregates (right) under a UV lamp is shown in Figure 1, indicating that polysilole nanoaggregates are more highly fluorescent than polysiloles at identical concentration.

For polysilole solution in pure THF, the photolumine-

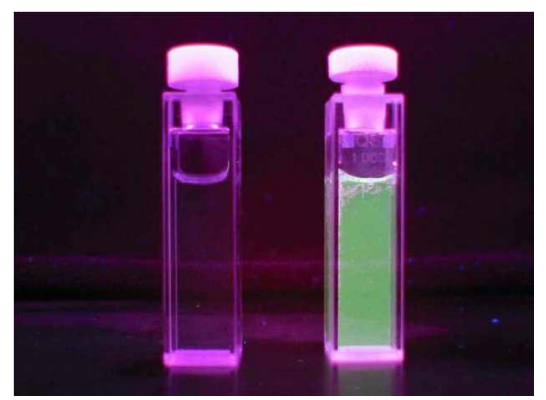

Figure 1. Photograph of polysilole in THF (10 mg/L, left) and polysilole nanoaggregates in water-THF misture $(90: 10$ by volume, $10 \mathrm{mg} / \mathrm{L}$, right) under blacklight.

scence (PL) intensity is very weak and an emission peak near $520 \mathrm{~nm}$ was observed. In solutions between $0 \%$ and $40 \%$ water by volume the emission intensity of polysilole nanoaggregates does not increased. However the intensity of the emission band increases by about 17.8 times when the solution is $99 \%$ water by volume. As the water fraction is increased. the emission intensity of polysilole nanoaggregates increases dramatically with no shift in the emission wavelength. Polysilole nanoaggregates in water-THF mixtures with $50 \%-99 \%$ water by volume exhibit one emission band at $513 \mathrm{~nm}$ when excited at $340 \mathrm{~nm}$ as shown in Figure 2. The emission band of polysilole nanoaggregates in water-THF mixtures is blue shifted by $7 \mathrm{~nm}$ compared to that of polysilole in THF. A minimum volume-fraction of $50 \%$ water is required to increase the luminescence. which indicates the

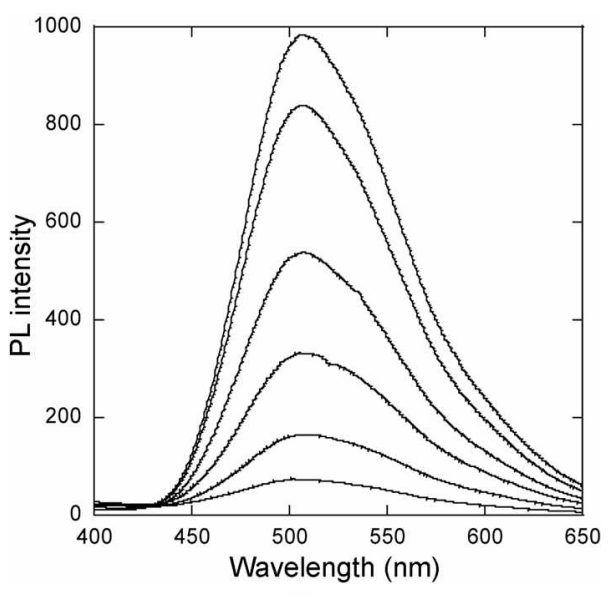

Figure 2. Fluoresience spectra of polysilole aggregates in water-THF mixtures $(\%$ water from top, $99 \%, 90 \%, 80 \%, 70 \%, 60 \%, 50 \%$ ). 


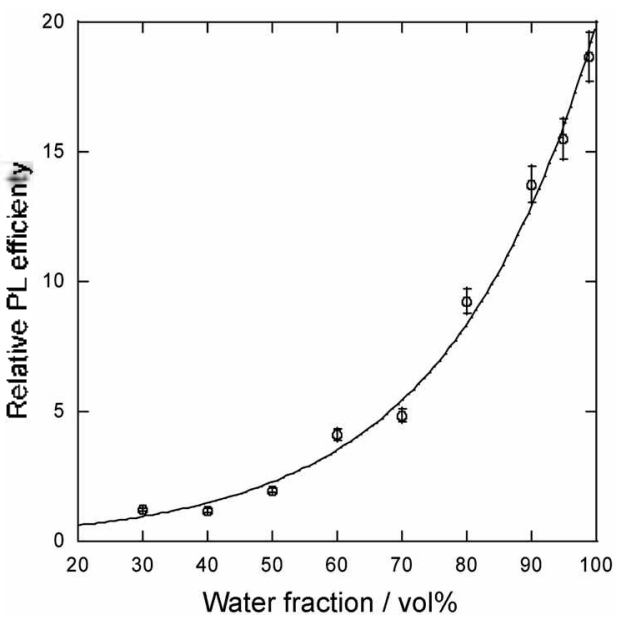

Figure 3. Plot of the relative mitensity of polysilole aggregates vs $\%$ water by volume.

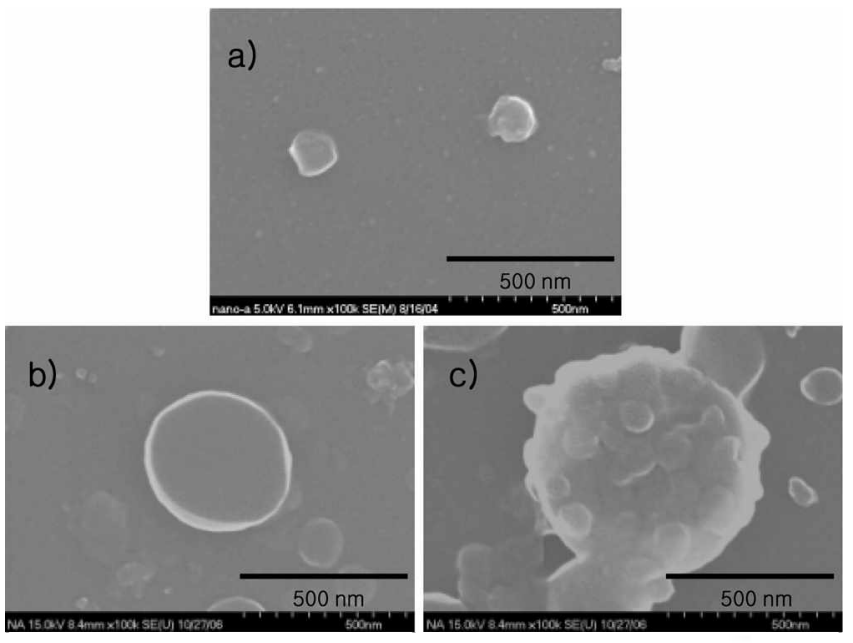

Figure 4. FE-SEM inages of polysilole nanoparticles from (a) $90 \%$, (b) $80 \%$, and (c) $70 \%$ water fraction.

onset of aggregation. This critical water concentration is that observed with other silole monomers. ${ }^{\text {'( }}$ The large increase in photoluminescence from polysilole aggregates could be attributed to the restricted rotation of the phenyl rings. which limits the nonradiative decay pathway's ${ }^{13}$ or inhibits the solvent assisted quenching resulting from aggregation. Figure 3 shows the plot for the relative PL intensity of polysilole nanoaggregate is \% water by volume. When the water fraction increases the emission intensity increases exponentially, indicating that the luminescence intensity is proportional to the percent of aggregated polysilole. The stability of poly silole nanoaggregates in $90 \%$ water solutions has been investigated and the PL intensity remains unchanged over a month. This indicates that polysilole nanoaggregates show neither further aggregation nor degradation.

Figure 4. obtained by cold field emission scanning electron micrography (FE-SEM. Hitachi: S-4700) shows the image of polysilole nanoaggregates in different water fractions. Aggregates of 1 consist of particles on the order of 20 num in diameter in $90 \%$ water solution. as determined by dynamic light scattering measurements (Particle Size Analyzer. Microtrac: UPA150). Particle diameter appears to vary with water fraction. but the dispersity of diameter for given any suspension is about $\pm 3 \%$. Particle diameters are around 700 $\mathrm{nm}$ for 50 to $70 \%$ water volume fraction and near $400 \mathrm{~nm}$ for $80 \%$ water. but they decrease dramatically above $80 \%$ water. Poly silole nanoaggregates exhibit a minimum in size at $90 \%$ water. A possible explanation is that at higher water concentrations the organic molecules aggregate to a higher extent in the hydrophilic environment. but THF absorbing into the aggregate causes them to swell at lower water concentrations. UV-vis spectra were obtained using Hewlett-Packard 8452A diode array spectrometer. UV-vis absorption and fluorescence spectra were measured for the polysilole in THF. Polysilole exhibits three absorption bands. which are assigned to the $\pi-\pi^{*}(364 \mathrm{~mm})$ transition in the silole ring and the $\sigma\left(\sigma_{2}^{*}+\pi^{*}\right)$ $(314 \mathrm{~nm})$ and $\sigma \sigma^{*}(260 \mathrm{~lm})$ transitions in the $\mathrm{Si}-\mathrm{Si}$ backbones. UV-vis absorption spectra of polysilole nanoaggregates have the same absorption band as the silole (2) in THF, but the $\pi-\pi$ transition red shifts as the percent water increases. In $90 \%$ water solutions. the $\pi-\pi$ transition of poly silole aggregates occurs at $374 \mathrm{~nm}$.

In conclusion, polysilole nanoaggregates exhibit an aggregation-induced emission enhancement with an intensity of 17.8 times to that of normal photoluminescence when the water fraction is increased to $99 \%$. The photoluminescence intensity of polysilole is exponential to the percent of water fraction and particle diameter is dependent on solvent composition.

Acknowledgment. This work was supported by Korea Research Foundation Grant (KRF-2004-015-C00263).

\section{References}

1. West, R.: Sohn, H: Bankwitz, U.; Calabrese, J.: Apeloig, Y: Mueller. T. J. Am Chem Soc. 1995. 117, 11608-11609.

2. Tamao. K.: Uchida. M: Izumizawa, T; Furukawa, K: Yamaguchi. S. J. Am. Chem. Soc. 1996. 118. 11974-11975.

3. Sohn1. H.: Huddleston. R. R.: Powell. D. R.: West. R.: Oka. K.: Yonghua. X. J. Am. Chem. Soc. 1999. 121.2935-2936

4. Xu. Y: Fujino. T: Naito. H.: Dohmaru. T.: Oka. K.: Sohn. H.: West, R. Jph. d. Appl. Phys. 1999, 38,6915-6918.

5. Yamaguchi. S.: Jin, R. Z.: Tamao, K. J. Am. Chem. Soc, 1999. 121. $2937-2938$

6. Soht1. H.: Calhout1. R. M.: Sailor. M. T.: Trogler. W. C. Angew: Chent. Int. Ed 2001. H. 2104-2105.

7. Sohn1. H.: Sailor. M. T.: Magde. D.: Trogler. W. C. J. Ant Chent. Soc. 2003, 125, 3821-3830.

8. Jakubiak, R; Bao, Z.: Rothberg, L. Synth. Mfat. 2000. 114. 6164.

9. Deans. R.: Kiml. T.: Machacek. M. R.: Swager. T. M. J. Am. Chent. Soc. 2000. 122.8565-8566.

10. Luo. J.: Xie. Z.: Lam. T. W.: Cheng. L.: Chen. H.: Qiu. C.: Kwok. H. S.; Zhan. X.: Liu, Y; Zhu, D.: Tang. S. Z. Chem. Commum. 2001. $115,1740-1741$.

11. Palilis, L. C.: Maekinen. A. J; Uchida. M; Kafafi. Z. H. Appt. Pho Lett. 2013. 14. 2209-2210.

12. Anl. B.-K.: Kwonl. S.-K.: Iung. S.-D.: Park. S. Y. J. Am Chent Soc. 2002. 124. 14410-14415.

13. Lee. M. H. Kim. D.: Dong. Y: Tang, B. Z. J. Komam Phys. Soc. 2004. $45,329-332$. 